\title{
Crime e castigo: breves notas sobre presídios brasileiros e penas alternativas
}

\section{Crime and punishment: brief notes on brazilian prisons and alternative sentences}

\author{
Roberto Remígio Florêncio betoremigio@yahoo.com.br \\ 2 Enio Silva da Costa
}

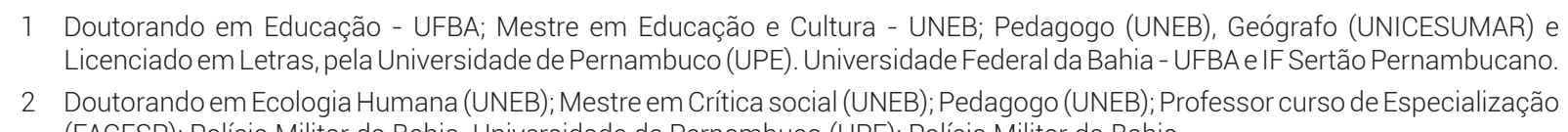
(FACESP); Polícia Militar da Bahia. Universidade de Pernambuco (UPE); Polícia Militar da Bahia.

\section{RESUMO}

Os presídios brasileiros são lugares de depósitos de seres humanos, históricos e duplamente marginalizados pela sociedade. O desprezo aos internos do sistema carcerário brasileiro e o preconceito aos egressos desse sistema dificultam o processo de ressocialização e entrada ou retorno ao mundo do trabalho e da dignidade. O presente manuscrito objetiva lançar uma luz sobre as propostas de alternativas às penas de prisão, ao tempo que indica possibilidades de mudanças paradigmáticas em relação aos encarcerados. A metodologia é baseada na revisão bibliográfica e análise documental, tendo como suporte a Legislação Prisional atualizada, observando as normas e os decretos que versam sobre a aplicação de penas alternativas e o sistema educacional dentro dos presídios. Nas conclusões, os autores apontam para a formação de uma consciência humanizada sobre a mercantilização das vidas encarceradas, em relação direta com o processo de educação para a vida, dentro e fora dos presídios brasileiros.

Palavras-chave:

Legislação. Políticas públicas. Ressocialização. Educação.

\section{ABSTRACT}

Brazilian prisons are places of human beings deposits, historically and doubly marginalized by society. The contempt for the inmates of the Brazilian prison system and the prejudice against those discharged from this system hinder the process of re-socialization, entry or return to the world of work and dignity. The present manuscript aims to shed light on the proposals for alternatives to prison sentences, while indicating possibilities for paradigmatic changes in relation to prisoners. The methodology is based on bibliographic review and documentary analysis, supporting the updated Prison Legislation, observing the rules and decrees that deal with the application of alternative penalties and the educational system within prisons. In the conclusions, the authors point to the formation of a humanized conscience about the commercialization of incarcerated lives, in direct relation to the process of education for life, inside and outside Brazilian prisons.

\section{Keywords:}

Legislation. Public policy. Resocialization. Education.

\section{Como você deve citar?}

FLORÊNCIO, Roberto Remígio; COSTA, Enio Silva da. Crime e castigo: breves notas sobre presídios brasileiros e penas alternativas. Cadernos UniFOA, Volta Redonda, n. 45, p. 69-77, abril 2021. 


\section{INTRODUÇÃO}

O surgimento do sistema prisional brasileiro nos remete ao período da chegada dos portugueses e, segundo Carvalho Filho (2002), há relatos que já existiam cadeias bem estruturadas em Salvador, no ano de 1550. As prisões eram instaladas nos andares térreos ou subsolos das câmaras municipais ou outros prédios públicos e faziam parte constitutiva do poder. A princípio não eram destinadas ao cumprimento de penas tal como se caracteriza a prisão na atualidade, mas eram espaços destinados principalmente aos escravos fugitivos. Não eram cercadas por muros e os presos mantinham contato com os transeuntes. Através das grades recebiam esmolas, alimentos e informações (CARVALHO FILHO, 2002, p. 35-36).

Após 500 anos, as prisões no Brasil ainda conservam o aspecto peculiar de ser um lugar para guardar "escravos", desordeiros, desocupados e outras classes ligadas aos pobres marginalizados. (CARVALHO FILHO, 2002, p. 37). Pessoas que, para o Estado e parte da sociedade, não merecem algum tipo de compaixão. Para muitos, a prisão é o lugar reservado aos não humanos, às "bestas-feras" que aterrorizam a sociedade. 0 desprezo aos internos do sistema prisional continua o mesmo, embora diante de toda 'humanização' da sociedade contemporânea. Não há sensibilização suficiente para provocar uma mobilização eficaz face às condições de saúde deploráveis, os ambientes superlotados em condições precárias e a ausência de projetos de fato ressocializadores. É importante salientar que a crise no sistema prisional não é um problema só dos presos, é um problema da sociedade, que passará a sofrer o agravamento das consequências de sua própria omissão.

Segundo Lemgruber (2002), o Estado Brasileiro tem sido historicamente incompetente e omisso na manutenção e gestão das instituições carcerárias, principalmente ao não oferecer possibilidades reais de ressocialização aos internos. Na maioria das unidades, não há espaços para duas importantes atividades de reinserção de egressos à vida social, autônoma e digna: a educação e o trabalho. Portanto, este estudo baseado em revisão bibliográfica, objetiva lançar uma luz sobre as condições desumanas em que vivem os apenados do sistema carcerário brasileiro, levando em consideração as atuais propostas de penas alternativas, como possibilidades de mudanças paradigmáticas em relação aos encarcerados, e uma apresentação da Legislação que rege esse setor, tão importante quanto discriminado da segurança pública e da construção sociocultural brasileira.

\section{O CONTEXTO PRISIONAL BRASILEIRO: ENTRE GRADES E PRECONCEITOS}

Somos cotidianamente acordados com as rebeliões e motins nas prisões brasileiras, que, na sua grande maioria, são fruto do sentimento de injustiça, de esquecimento e desumanidade sofrido pelos sujeitos privados de liberdade. A mídia, no exercício da sua função de controle social, gera, muitas vezes, o embrutecimento das massas, quando trata tal situação, tendo em vista apenas o lado transgressor/ violador das rebeliões por parte dos presos, sem que determinados elementos, como as precárias condições de vida no cárcere, apareçam como causas das revoltas, como afirma Carvalho Filho (2002, p. 8), citando uma matéria publicada no Jornal Folha de São Paulo que relata que,

[...] em 18 de fevereiro de 2001, o Brasil era surpreendido por uma super-rebelião de presos. Sob a regência da organização criminosa Primeiro Comando da Capital (PCC), que se notabilizara pela prática de atos de violência e fugas sensacionais, 28 mil detentos de 29 unidades prisionais do estado de São Paulo, em 19 cidades amotinaram-se ao mesmo tempo. A Secretaria de Assuntos Penitenciários só readquiriu o controle da situação 27 horas depois e contabilizou 16 mortos. [...] os itens da pauta diziam a respeito ao tratamento que todos recebem: fim da tortura, punição de agentes penitenciários por abuso de poder e espancamentos, melhoria da assistência jurídica gratuita e fim das revistas vexatórias das visitas (CARVALHO FILHO, 2002, p. 9). 
A questão é complexa e exige da sociedade um debate apurado e desprovido de preconceitos e estigmas. Se o sujeito cometeu um crime e a prisão é o lugar-espaço para expiar por esse crime, esse lugar precisa estar em condições humanas para receber seres humanos. Senão, não há como esperar ressocialização e transformação positiva. De fato, as cadeias e presídios brasileiros não cumprem a contento os artigos da Lei de Execução Penal, sobretudo o artigo art. $5^{\circ}$, que prevê a classificação e a separação dos presos conforme seus antecedentes e sua personalidade. Essa lei pressupõe naturalmente que a população carcerária não é homogênea e que apresenta as mesmas diferenças e padrões de comportamento característicos da sociedade de que provêm. E essa classificação é fundamental para que se estabeleça um programa individualizado para a execução da pena de prisão aplicada.

A classificação ou individualização da pena é essencial para que não aconteça o que alguns chamam de "contaminação", ou seja, que a convivência carcerária entre os diversos tipos de encarcerados faça nascer "um novo detento", que se fabrique um novo delinquente. A Constituição de 1824 já determinava que as prisões tivessem os apenados separados por tipo de crime ou pena.

Para Wacquant (2001), as prisões no Brasil encontram-se entre as piores do mundo em relação às condições de encarceramento. No que tange ao imenso número de presídios, encontra-se no nível das prisões do Primeiro Mundo.

[...] O Sistema Penitenciário Brasileiro acumula com efeito as taras das piores jaulas do Terceiro Mundo, mas levadas a uma escala digna do Primeiro Mundo, por sua dimensão e pela indiferença estudada dos políticos e do público: entupimento estarrecedor dos estabelecimentos [...]; negação de acesso à assistência jurídica e aos cuidados elementares de saúde, [...]; violência pandêmica entre detentos, sob forma de maus-tratos, extorsões, sovas, estupros e assassinatos, em razão da superlotação super acentuada, da ausência de separação entre as diversas categorias de criminosos, da inatividade forçada [...] e das carências de supervisão (WACQUANT, 2001, p. 11).

Ao dizer que, no Brasil, as prisões têm uma escala digna de primeiro mundo, Wacquant está remetendo-se ao crescimento vertiginoso de estabelecimentos prisionais no país em consequência do aumento da população carcerária, fenômeno que também ocorre na Europa, tendo como modelo a expansão carcerária dos Estados Unidos.

Entre 2000 e 2010, a população prisional, no Brasil, cresceu abruptamente de 232.760 para quase 500.000 , mais que o dobro em uma década. Isso foi acompanhado de um acentuado crescimento da taxa encarceramento, de 137,27 para 258 por 100.000 habitantes $^{3}$.

Segundo Monteiro e Cardoso (2012), esse aumento da população prisional, tanto em termos absolutos quanto em termos relativos, é menos o reflexo do crescimento das taxas criminais per se mais o resultado de políticas de sentenças judiciais ou provimentos legais que aprisionam suspeitos e criminosos de forma rotineira, que são moldadas por uma ideologia prevalente de que a prisão "funciona" pela falta de alternativas (TEOTÔNIO, 2016).

Tanto a sociedade quanto os operadores do direito precisam conceber, nos sujeitos privados de liberdade - um ser humano, que o cometimento do crime não o desqualifica enquanto ser humano. Isso se faz fundamental para que não predomine o sentimento descrito por Lima (2001, p. 107): "o preso é alguém tão despojado, tão despossuído, que sua conquista do direito à voz soa como anúncio da inevitável desestabilização, do caos, da insegurança coletiva".

Enfım, mais do que humanizar as condições do encarceramento, é preciso proporcionar aos internos do sistema prisional condições dignas de reintegração social, oportunidades educacionais,

3 Departamento Penitenciário Nacional. Disponível em: http://portal.mi.gov.br. Acesso em: 20 fev. 2011. 
profissionais, e, para que esse expediente seja revisto pela sociedade de magistrados, é necessário o exercício regular do estudo e da utilização das outras formas de punir, que, infelizmente, ainda não é unanimidade entre magistrados que, por sua vez, não desejam usá-las por desconhecimento, receio da opinião pública ou meramente atitude de preconceito.

Entretanto, é importante salientar que algumas mudanças começam a acontecer, ainda que timidamente, como nos casos da aplicação das penas alternativas e da justiça restaurativa, assim como da participação de alguns setores da sociedade civil organizada em promover debates, discutir as condições de existência no cárcere, criando grupos de trabalho para propor intervenções no sistema como um todo, como mostraremos no decorrer deste trabalho.

\section{MAIS CIDADÃOS, MENOS PRESOS: UMA LÓGICA EQUAÇÃO}

Indiscutivelmente a prisão não pode ser encarada como a panaceia para resolver o problema da criminalidade, assim como o encarceramento não pode ser a forma mais eficaz de responsabilizar todos os sujeitos que cometeram delitos.

A pena privativa de liberdade surgiu com objetivo de substituir as penas violentas e cruéis antes existentes. Reza a crítica que a crença na recuperação do criminoso via pena privativa de liberdade é uma utopia.

As críticas ao sistema prisional, tal qual ele funciona hoje, são claras, ao afirmar que o encarceramento como medida para ressocialização ou reeducação não tem surtido efeito desejável. Lima (2001), que esteve durante parte da sua vida encarcerado, traduz bem o que são as prisões brasileiras, a sua ineficácia e o seu custo dispendioso para a população.

[...] A falta de sensibilidade daqueles que comandam os destinos do país em ouvir a voz das prisões faz com que rebeliões pipoquem país afora, somos quase meio milhão de encarcerados e foragidos, muitos tentando a duras penas sobreviver, não permitindo a marginalização das suas famílias, se jogando às feras para que seus filhos não engrossem o batalhão de jovens sem futuro que passam seus dias a envelhecerem nas prisões sem perspectiva de nada, ficam no vácuo do tempo a espera do que não sabem (LIMA, 2001, p. 127).

As vozes dos invisíveis ecoam através dos motins, rebeliões e violências, provocando a sociedade a buscar e a refletir sobre a existência da prisão na atualidade. A prisão pode servir somente para a segregação ou a privação da liberdade dos sujeitos consideravelmente perigosos, contendo o Estado, a sociedade e os operadores do direito, da lógica de que a vingança penitenciária é a forma mais adequada de punir todos os delinquentes.

Como resultado desse processo, é o fato de que existem milhares de pessoas encarceradas que poderiam estar, em virtude da idade e de vínculos familiares ainda presentes, sob o foco de outras modalidades de controle estatal. "É muito mais barato instruir programas de monitoramento eficazes de condenados do que construir presídios" (CARVALHO FILHO, 2002, p. 68), que, em virtude da lógica predominante e já destacada neste trabalho, acabam por virar "escolas do crime".

A punição está vinculada aos possíveis danos à ordem social que o crime acarreta e não aos danos materiais propriamente ocorridos. Dessa forma, a punição e o sistema carcerário entraram de tal maneira no imaginário social que passou a ser considerado legítimo aquele que pune, deixando de ser escandaloso o castigo, fazendo com que ambos caminhem juntos e se fundam nos presídios, onde a punição legal vem acompanhada dos castigos extralegais. 
Para um mal necessário que é a prisão, um bem essencial são as penas restritivas, popularmente chamadas de "penas alternativas". Essa modalidade de pena - adotada pela primeira vez na Rússia, em 1926 - foi implantada no Brasil em 1984, a partir da lei 7.209/84. Só podem ser aplicadas aos crimes de menor e médio potencial ofensivo, como penas de, no máximo, quatro anos ou réus primários.

Segundo a Legislação, "o julgador poderá aplicar tanto a pena privativa de liberdade quanto a pena restritiva de direitos, valendo-se do que considerar mais adequado" (BRASIL, 1998/2012). É preciso compreender contextualmente o Código Penal Brasileiro, quando registra que,

uma vez condenado o réu, o juiz sempre aplicará a pena privativa de liberdade, e, verificando o tempo que o sujeito foi condenado e as circunstâncias exclusivas do caso, o magistrado a substituirá por uma pena restritiva de direitos. Daí a natureza substitutiva de tais penas. Tal situação ocorre pela seguinte razão: as penas restritivas de direitos estão previstas no Código Penal, logo não podem ser aplicadas diretamente, portanto, o juiz aplica a pena privativa de liberdade, e se presentes os requisitos legais, ele a substituirá pela restritiva de direitos (BRASIL, Lei $9.714,1989 / 2012)$.

No VII Congresso das Nações Unidas para a Prevenção do Crime e Tratamento dos Delinquentes, realizado no ano de 1985, em Beijing/China, expediu-se a Resolução 16, enfatizando a necessidade da redução do número de reclusos, de soluções alternativas à prisão e da reinserção social dos delinquentes. O Pacto Internacional dos Direitos Políticos e Civis e a Declaração Universal dos Direitos do Homem vieram consubstanciar as experiências das Nações Unidas no terreno da implantação, execução e fiscalização das medidas alternativas à pena privativa de liberdade.

Ninguém ganha com pessoas presas e o custo social tem se mostrado alto e ineficiente. Entre tantos fatores adversos à pena de prisão, está inclusive o seu pretenso objetivo de ressocializar os sujeitos, que durante sua estada na prisão é imerso em procedimentos, atitudes e comportamentos que os tornam bons presos para o sistema prisional e incapazes para o retorno ao convívio social no exercício pleno da cidadania. A questão se agrava com o divórcio da política criminal e penitenciária com as políticas sociais, principalmente a educacional. Nessa perspectiva, a proposta de ressocialização contida na Lei de Execução Penal - LEP não tem sentido, pois o número de reincidentes não é levado em conta. Estima-se que mais de $80 \%$ reincidam, mas os diretores dos estabelecimentos penais e as empresas que administram as unidades não são questionados quantos aos números da reincidência, embora, quando ocorrem motins, rebeliões ou fugas, os gestores sejam imediatamente substituídos ou os contratos das empresas sejam rescindidos. Por isso, Leme (2007) reafirma que a prisão tem se configurado apenas como espaço de punição.

\section{ALGUMAS NOTAS SOBRE PENAS ALTERNATIVAS}

Segundo Teotônio (2016), as penas alternativas representam os meios mais eficazes de prevenir a reincidência criminal, "devido ao seu caráter educativo e socialmente útil, pois enseja que o infrator cumpra sua pena em 'liberdade"'. Estando em monitoramento pelo Estado e também pela sociedade, acredita-se que é o caminho mais viável, além de menos oneroso, à reintegração social de uma pessoa apenada. Entretanto, esse processo deve estar associado ao tipo de crime, à conduta do indivíduo e ao comportamento em sociedade. Nesse sentido, em palestra durante III Seminário Internacional de Políticas Sociais $^{4}$, realizado em Salvador/BA, a conselheira do Conselho Nacional de Política Criminal e Penitenciária - CNPCP, Valdirene Daufemback, menciona um caso no Acre em que um Juiz condenou uma jovem a uma pena de 4 anos e 3 meses de prisão por furto de fraldas descartáveis (furto com

4 III Seminário Internacional em Políticas Sociais e Cidadania, realizado entre os dias 24 a 26/11/2010, em Salvador, promovido pelo mestrado em Políticas Sociais e Cidadania da Universidade Católica de Salvador.. 
abuso de confiança). O custo anual dessa jovem na Penitenciária de Rio Branco foi de R\$ 13.320,00 e o valor do furto, $\mathrm{R} \$ 16,00$. Caso fosse aplicada pena alternativa, o custo seria, no máximo, $5 \%$ desse valor.

O Código Penal Brasileiro sofreu sérias modificações por conta da Lei 9.714/98, que se destacou pela criação das penas restritivas de direitos, tais como:

Prestação pecuniária: também conhecida como indenização pecuniária. Consiste no pagamento a vítima, a seus dependentes ou a entidade pública ou privada de destinação social de uma importância em dinheiro a ser fixada pelo juiz;

Perda de bens e valores do condenado: esse expediente tem como teto o montante de prejuízo causado ou do proveito obtido com crime;

Prestação de serviço à comunidade: para substituir a pena de prisão superior a 6 meses, essa prestação de serviços consiste na realização de tarefas pelo condenado em hospitais, escolas, creches etc. Para não prejudicar a jornada normal de trabalho, a pena é cumprida à razão de uma hora de tarefa por um dia de condenação;

Interdição temporária de direitos: punição que consiste na proibição de exercer cargos ou função pública, inclusive mandato eletivo, e de exercer determinadas profissões que dependem de habilitação especial, em suspensão da habilitação para dirigir veículos e na obrigação de não frequentar determinado lugares;

Limitação de final de semana: consiste na obrigatoriedade de permanecer aos sábados e domingos, por cinco horas diárias em casa de albergado ou outro estabelecimento similar. Essa medida é criticada por dois motivos: primeiro porque casas de albergado quase não existem, depois porque onde existem, abrigam presos oriundos do sistema penitenciário em regime aberto, o que seria um contrassenso a convivência dos diversos tipos de condenados no mesmo espaço.

Diante do descalabro que perdura no sistema prisional, penas alternativas são experiências inovadoras como iniciativas para se encontrar maneiras humanizadas de operacionalizar as punições e evitar a prisão em um sistema carcerário caótico. Entretanto, não podem ser vistas como medidas a favor da impunidade, sim como outra forma de reconhecer o crime, o criminoso e o local de abrigo dele. Longe de ser uma questão apenas policial ou judiciária, deve ser visto como um problema de toda a sociedade, que assume as consequências da política do encarceramento indiscriminado, sobretudo o ônus de custear as "fábricas de criminosos" ou de contribuir para as violações dos direitos humanos, que são as prisões brasileiras.

O importante é que a sociedade possa participar e compreender que, nos conflitos sociais ou nos delitos, sempre existirão prejuízos pessoais, sociais, econômicos, e que a busca pela culpabilidade quase sempre desembocará no agravamento sofrido tanto pela "vitima" quanto pelo "criminoso". Algumas mudanças começam a acontecer, ainda que timidamente, como nos casos da aplicação das penas alternativas e da justiça restaurativa, assim como da participação de alguns setores da sociedade civil organizada em promover debates, discutir as condições de existência no cárcere, criando grupos de trabalho para propor intervenções no sistema prisional.

Educação e trabalho são duas importantes categorias que permeiam a discussão sobre programas de ressocialização no sistema penitenciário, incluindo aí a alternativa perene de concessão de penas diferenciadas do simples encarceramento. Ainda que vistas de formas diferenciadas por juristas e legisladores, as penas alternativas têm obtido aval de um número cada vez maior de simpatizantes, juntamente com as atividades educativas e laborais dentro e fora dos presídios, como programas de ressocialização. Atualmente, é seguro afirmar que predomina o consenso de que a educação e a preparação para o mundo do trabalho 
devem estar articuladas, porém esta sempre foi uma realidade fora do sistema prisional. Embora, do lado de fora, o preconceito, conceito oposto à educação, ainda precisa ser fortemente combatido.

Educação e trabalho são duas importantes categorias que permeiam toda a discussão sobre programas de ressocialização no sistema penitenciário, ainda que vistos de formas diferentes, em razão pela qual muitos valorizam o trabalho como proposta de programa de ressocialização. Entretanto, hoje, predomina o consenso que tanto a educação quanto a preparação para o mundo do trabalho devem estar articulados (JULIÃO, 2006, p. 79-80), ainda que muitos fatores colaborem para que educação e trabalho estejam em lados opostos, sendo "concorrentes", como assinala Leme (2007, p. 154).

Não podemos esquecer que o trabalho nas prisões ainda é uma grande concorrente da escola. No momento de escolher entre o trabalho e o estudo, sem hesitar, a maioria dos prisioneiros escolherá o trabalho. Se o trabalho fornece o alimento e a educação fornece o sentido, o alimento ainda é a necessidade mais imediata, não só para os prisioneiros, para a maioria da população.

Lamentavelmente para muitos resta a imposição de decidir pelo trabalho, pela sobrevivência, dilema que os acompanha antes do cárcere, e enfrenta o mesmo "escolher" entre trabalhar e estudar na realidade carcerária. Mesmo com a situação em que os internos optam pelo trabalho, não é um trabalho assalariado e com remuneração compatível, mas a única forma de trabalho desenvolvido dentro do sistema prisional, atividades de limpeza, artesanato e outros serviços. Em muitos casos, há exploração da mão de obra barata que não está sujeita a encargos sociais, como reza o artigo 28, da Lei de Execução Penal (BRASIL, 1997). Ainda que se considere tais limites, investir em uma educação para o trabalho ou articulada com o ensino técnico profissional é uma necessidade no contexto prisional.

\section{CONSIDERAÇÕES FINAIS}

O Código Penal Brasileiro sofreu sérias modificações por conta da Lei 9.714/98. Abriu-se um horizonte infindável para responsabilizar os sujeitos pelos delitos cometidos, sem necessariamente recorrer à pena de prisão, desonerando o Estado e contribuindo imensuravelmente para a não reincidência e a inserção social. Como afirma Carvalho Filho (2002, p. 68): "a prisão pode ser estrategicamente reservada para situações em que a liberdade do condenado constitui ameaça concreta, quando não há alternativa possível". A prisão não pode ser lugar-espaço para que o Estado exerça a sua sede de vingança e como fonte de lucro para o capital, pois a intervenção da Justiça Criminal tem por objetivo prevenir o delito, promover a segregação punitiva do infrator, constituindo a última reação do Estado em face à criminalidade. Isso consubstancia a importância da aplicação de penas alternativas e da reinserção do infrator na sociedade sem se esquecer da reparação do dano causado à vítima.

Urge a necessidade de transformar em agenda política a situação precária do sistema prisional, promover debate com a sociedade, mobilizar para reformar de fato o sistema que se encontra falido desde o seu surgimento. Parece que, enquanto a prisão existir somente para os despossuídos, não há preocupação em reformar. Lima (2001, p. 119) expõe o drama vivido e o que de fato é o sistema prisional brasileiro e as consequências de um modelo punitivo fracassado ou vitorioso em seus intentos desumanos.

Cerca de $10 \%$ da população carcerária do país participa atualmente de algum tipo de atividade educacional. A expectativa é que a aprovação da proposta (a remição pelo estudo) estimule a formação escolar dos presos, já que a maioria possui baixa escolaridade - apenas $7 \%$ concluíram o ensino médio e $66 \%$ não completaram sequer o ensino fundamental ${ }^{5}$.

5 De acordo com o Departamento Penitenciário Nacional - DEPEN, devem ser oferecidas aos encarcerados, aulas nos níveis Fundamental e Médio, desde a LEP (Lei de Execução Penal), de 1984 - Disponível em: http://portal.mi.gov.br. Acesso em: 20 set. 2019 . 
Tanto a sociedade quanto os operadores do direito precisam conceber, nos sujeitos privados de liberdade - um ser humano, que o cometimento do crime não o desqualifica enquanto ser humano. Isso se faz fundamental para que não predomine o sentimento descrito por Lima (2001, p. 107): "o preso é alguém tão despojado, tão despossuído, que sua conquista do direito à voz soa como anúncio da inevitável desestabilização, do caos, da insegurança coletiva".

Enfım, mais do que humanizar as condições do encarceramento, é preciso proporcionar aos internos do SPB condições dignas de reintegração social, oportunidades educacionais, profissionais e, sobretudo, o exercício regular das outras formas de punir, que infelizmente os magistrados ainda não usam ou não desejam usá-las.

\section{REFERÊNCIAS}

BRASIL. Lei de Execuções Penais. Lei n 7.210, de 11 de julho de 1984. Publicado no Diário Oficial da União. 1984. São Paulo: Saraiva, 1997.

BRASIL. Código Penal Brasileiro. Lei 7.419/1998. Readaptada em 2012. Ministério da Justiça do Brasil. Disponível em https://www.tjdft.jus.br/institucional/imprensa/campanhas-e-produtos/direito-facil/ edicao-semanal/pena-privativa-de-liberdade-x-pena-restritiva-de-direitos. Acesso em: 20 maio 2011.

CAPELLER, W. O Direito pelo avesso: análise do conceito de ressocialização. Temas IMESC: Soc. Dir. Saúde. São Paulo: v. 2, n. 2, p. 127-134, 1985.

CARVALHO FILHO, Luis Francisco. A prisão. São Paulo: Publifolha, 2002.

COSTA, Enio Silva da. A Desconstrução do sujeito: narrativas e modos de vida dentro da prisão. Dissertação de Mestrado do Programa de Pós-graduação em Crítica Cultural - PPGCC/UNEB. Alagoinhas/BA, 2011.

FREIRE, Paulo. Política e educação: Ensaios. 2. ed. São Paulo: Cortez Editora, 1995.

FREIRE, Paulo. Pedagogia do oprimido. Rio de Janeiro: Paz e Terra, 2005.

GADOTTI, Moacir. Palestra de encerramento. In: MAIDA, M. J. D. (Org.). Presídios e Educação. São Paulo: FUNAP, 1993, p. 121-148.

GADOTTI, Moacir. Manicômios, prisões e conventos. São Paulo: Perspectiva, 2008.

JULIÃO, Elionaldo Fernandes. Escola da prisão: espaço de construção da identidade do homem aprisionado. In: Educação escolar entre as grades. Elenice Maria C. Onofre (org.) São Carlos: EduFSCar, 2007.

JULIÃO, Elionaldo Fernandes. Educação e Trabalho como propostas políticas de execução penal. Revista de Educação de Jovens e Adultos: Alfabetização e Cidadania. Brasília: RAAAB/ UNESCO/ Governo Japonês, 2006.

LEITE, José Ribeiro. Educação por trás das grades: uma contribuição ao trabalho educativo, ao preso e à sociedade. Dissertação (mestrado) - UNESP, Marília, 1997.

LEME, J. A. G. A cela de aula: Tirando a pena com letras. Uma reflexão sobre o sentido da educação nos presídios. In: Educação escolar entre as grades. Elenice Maria C. Onofre (org.). São Carlos: EdUFSCar, 2007. 
LEMGRUBER, Julita. Controle da criminalidade: mitos e fatos. São Paulo: Instituto Liberal, 2002.

LIMA, William da Silva. Quatrocentos contra um: uma história do Comando Vermelho, 2. ed., São Paulo: Labortexto Editorial, 2001.

MONTEIRO, Felipe Mattos; CARDOSO, Gabriela Ribeiro. Análise do sistema prisional brasileiro com base nos dados disponibilizados pelo Infopen nos anos de 2000 a 2007. In: $32^{\circ}$ Encontro Anual da Anpocs - 5 Painel do GT: Crime, Violência e Punição Sistema Prisional e Políticas Públicas. Brasília, 2012.

MOVIMENTO EDUCACIONISTA PAULISTA, 2008. Disponível em: http://www.uniso.br/hs/educacionismo/ docs/etica_moral_e_filosofia_educacionista. Acesso em: 20 maio 2011.

OLIVEIRA, Odete Maria de. Prisão: um paradoxo social. 3. ed. Florianópolis: UFSC, 2003.

ONOFRE, Maria Cammarosano (org.). Escola na prisão: espaço de construção da identidade do homem aprisionado? In: Educação escolar entre as grades. São Carlos: EduFSCar, 2007.

TEOTÔNIO, Paulo José Freire. Das penas substitutivas: o único caminho viável para o direito penal contemporâneo. Ribeirão Preto: Editora Magister, 2016.

THOMPSON, Augusto. A questão penitenciária. Rio de Janeiro: Ed. Forense, 2002. 